\title{
DECISION SUPPORT SYSTEM ASSESSING FEASIBILITY TAEKWONDO ATHLETE (UPN "VETERAN" YOGYAKARTA)
}

\author{
Nur Heri Cahyana ${ }^{1)}$, Fachrizal Herdiansyah Mawardana ${ }^{2)}$, Rifki Indra Perwira ${ }^{3)}$ \\ Jurusan Teknik Informatika, Fakultas Teknik Industri \\ UPN "Veteran" Yogyakarta \\ Jalan Babarsari 2 Tambakbayan \\ Email : ${ }^{1}$ dsnurheri@gmail.com, ${ }^{2}$ fachrizal.workmail@gmail.com, ${ }^{3}$ rifki@upnyk.ac.id
}

\begin{abstract}
Indonesian taekwondo athlete's achievements have improved because he managed to win several medals in international championships. Being a taekwondo athlete requires a willingness, discipline, good physical condition, experience, mental endurance, unyielding spirit, and proper posture. The assessment process is still done manually by asking taekwondo for their availability in the match; therefore, it requires a decision support system to measurement of participants (taekwondoin). Decision support is a way to provide problem-solving skills and be able to support the work of a coach in solving problems by giving suggestions towards certain decisions. The purpose of Simple Additive Weighting is to determine the feasibility of taekwondoin selection to become an athlete on the championship team. Dynamic criteria allow adding the criteria needed for coaches and managers. Coaches and managers also can refine taekwondo by adding the required criteria to the agreed additional criteria.The result of this paper is application can give the decision of athletes who deserve to enter the match team. To facilitate managers and coaches in screening the best athletes. The validation test results obtained 85\% compatibility between the selection results in the application and manual calculations.
\end{abstract}

Keywords: Dynamic criteria, SAW method, support system, taekwondo.

\section{Pendahuluan}

Prestasi atlet taekwondo Indonesia semakin meningkat menurut presiden World Taekwondo Federation (WTF) karena berhasil memperoleh beberapa medali dalam kejuaraan ajang internasional [1]. Menjadi atlet taekwondo membutuhkan kemauan, disiplin yang tinggi, kondisi fisik yang sehat, pengalaman, mental yang kuat, semangat pantang menyerah serta postur tubuh yang ideal. Seorang murid taekwondo atau Taekwondoin harus mempunyai hal - hal tersebut agar dinilai layak menjadi atlet taekwondo. Di tempat latihan taekwondo atau disebut dojang khususnya di dojang UPN "Veteran" Yogyakarta para taekwondoin yang ingin menjadi atlet dan masuk team atlet suatu pertandingan akan dinilai kelayakkannya, pada proses penilaian yang masih dilakukan secara manual, yaitu dilakukan dengan menanyakan kepada calon atlet atas ketersediannya mengikuti pertandingan yang akan berlangsung, lalu penilaian yang dilakukan oleh pelatih dengan mencatat penilaian latihan pada secarik kertas saat latihan berlangsung, hal ini menjadikan proses menilai kelayakan taekwondoin menjadi kurang objektif dan kurang informatif, selanjutnya jika pertandingan telah lama usai dan akan ada pertandingan selanjutnya, pelatih maupun manager tidak memiliki laporan dan rekam tentang penilaian calon atlet.

Pendukung keputusan mendayagunakan resources individu dengan kemampuan komputer untuk meningkatkan kualitas keputusan [2] serta dapat memberikan kemampuan pemecahan masalah dan mampu mendukung kerja seorang manajer ataupun sekelompok 
manajer dalam memecahkan masalah dengan cara memberi informasi atau usulan menuju keputusan tertentu, terdapat salah satu metode pada sistem pedukung keputusan yaitu metode Simple Additive Weighting (SAW) yang dikenal juga dengan metode penjumlahan terbobot [3]. Tujuan Simple Additive Weighting adalah untuk menentukan dalam penyeleksian kelayakkan taekwondoin menjadi atlet pada suatu kejuaraan. Pada penelitian kali ini dilakukan observasi dan wawancara dengan pelatih di dojang UPN "Veteran" Yogyakarta tentang kriteria dasar penilaian atlet taekwondo dojang UPN, dan didapat tujuh kriteria dasar penilaian yaitu kemauan motivasi, kedisiplinan, kondisi fisik, pengalaman, ketahanan mental, spirit (Semangat pantang menyerah), dan Postur tubuh. Jadi pada setiap penilaian akan diberi bobot dan dihitung, hasilnya kita akan mengetahui apakah taekwondoin tersebut layak menjadi atlet atau tidak. Metode Simple Additive Weighting (SAW) akan ditambahkan dengan Dynamic Criteria, dengan dynamic criteria memungkinkan menambahkan kriteria yang dibutuhkan bagi pelatih maupun manager, apabila terlalu banyak calon atlet yang memenuhi kriteria tetapi kuota dalam suatu pertandingan tersebut terbatas, pelatih dan manager dapat menyaring kembali para calon atlet tersebut dengan cara menambahkan kriteria yang diperlukan tetapi dengan keputusan yang telah disepakati bersama.

Wicaksono [4] mencari alternatif terbaik berdasarkan kriteria-kriteria yang telah ditentukan dengan menggunakan metode Simple Additive Weighting (SAW) untuk melakukan perhitungan pada kasus mencari alternatif tablet terbaik. Kriteria bersifat dinamis, nilai bobotnya dapat diubah sesuai keinginan user. Kemudian dilakukan proses perangkingan yang akan menentukan alternatif terbaik, yaitu tablet nilai fuzzy terbaik.

Penelitian lain yang telah dilakukan oleh Rasyid [5], yaitu membuat aplikasi dengan menggunakan beberapa metode simple additive weighting (SAW) dan metode simple multi attribute rating technique (SMART). Kriteria yang digunakan dalam menentukan pemberian beasiswa adalah nilai rata-rata, tanggungan orang tua, penghasilan orang tua, status keuangan dan usia. Pada aplikasi ini didapat kesimpulan menggunakan 50 data uji coba data sampel hasil dari kedua metode SAW dan SMART sama-sama memperoleh beasiswa, sistem perangkingan nilai akhir pada metode SAW mengurutkan nilai tertinggi sampai terendah dengan rekomendasi nilai tertinggi memperoleh beasiswa sedangkan pada metode SMART sistem penilaian akhirnya dengan menggunakan range apakah diterima, dipertimbangkan atau ditolak.

Jayanti [6] mengenai implementasi metode simple additive weighting (SAW) dan analytical hierarchy process (AHP) pada sistem informasi penilaian kinerja dosen, pada penelitian tersebut menggunakan metode SAW dan AHP untuk menghitung kinerja dosen, penelitian ini membutuhkan suatu metode yang dapat melibatkan banyak komponen atau kriteria yang dinilai (multi kriteria), sehingga dalam penyelesaiannya diperlukan sebuah sistem pendukung keputusan dengan multikriteria.

Jasril [7] tentang sistem pendukung keputusan pemilihan karyawan terbaik menggunakan metode fuzzy AHP, pada penelitian tersebut menggunakan metode fuzzy dan AHP untuk merangking dan mencari karyawan terbaik, penelitian ini menggunakan kriteria yang dinamis sehingga sistem dapat menangani jika terdapat suatu perubahan atau penambahan kriteria. Kontribusi penelitian ini adalah

1) Mengusulkan SAW dan Dynamic criteria sebagai pengembangan pendukung keputusan.

2) Dynamic criteria dapat dilakukan secara fleksibel

Berdasarkan penelitan terdahulu yang dirujuk dan dijadikan acuan, aplikasi yang akan dibuat pada penelitian ini dengan judul aplikasi kelayakkan siswa/i taekwondo menjandi atlet UPN "Veteran" Yogyakarta menggunakan metode simple additive weighting dengan dynamic criteria dalam partisipasi kejuaraan memiliki perbedaan pada objek yang diteliti dan 
memiliki pembaharuan yaitu memakai metode simple addtive weighting dengan dynamic criteria yaitu criteria yang dapat ditambahkan sesuai dengan kebutuhan, tetapi criteria dapat ditambahkan hanya jika dengan persetujuan bersama antara manager dengan pengurus dojang dan memiliki 7 criteria dasar yang didapat dari hasil wawancara oleh pelatih di UPN "Veteran" Yogyakarta. .

\section{Metodologi Penelitian}

Penelitian ini menggunakan jenis kualitatif karena berfokus pada subyek [9]. Pada analisa kebutuhan, hal yang dilakukan pertama kali adalah observasi yaitu melakukan tinjauan serta pengamatan langsung di taekwondo UPN "Veteran" Yogyakarta mengamati pada sistem yang berjalan dengan tujuan menentukan objek yang akan diteliti, menentukan data yang dibutuhkan, membuat hipotesa, membuat tujuan penelitian dan menentukan cara yang akan digunakan. Pada tahap pengumpulan data, dilakukan pengumpuan data dengan cara studi pustaka, observasi dan wawancara. Studi pustaka dilakukan sebagai bahan pencarian referensi terhadap masalah dan metode serta cara yang akan digunakan dalam penelitian. Metodologi pengembangan sistem menggunakan waterfall [8].

Adapun tahapan - tahapan yang akan dilaksanakan adalah sebagai berikut :

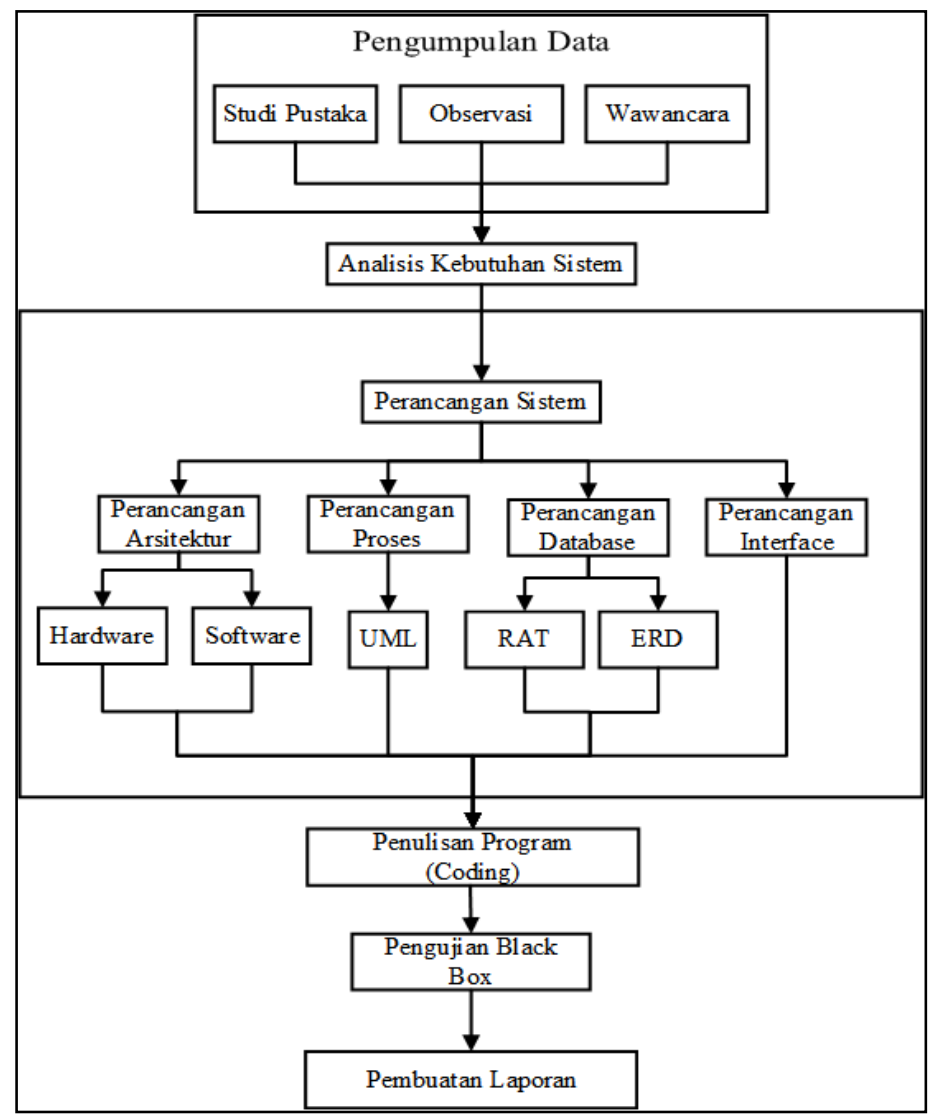

Gambar 1. Tahapan Penelitian

Berikut perhitungan manual yang dilakukan pada aplikasi penentuan kelayakkan siswa-siswi taekwondo menjadi atlet dojang UPN "Veteran" Yogyakarta menggunakan metode simple additive weighting dengan dynamic criteria dalam partisipasi kejuaraan dari proses yang dilakukan oleh sistem. Terdapat tujuh kriteria dasar pada Tabel 1 yang semuanya merupakan kriteria benefit, jika dibutuhkan penambahan kriteria, maka kriteria baru yang telah dibuat merupakan kriteria benefit juga. 
Tabel 1. Tabel kriteria dasar

\begin{tabular}{|l|l|l|l|}
\hline No. & Simbol & Keterangan & bobot \\
\hline 1 & $\mathrm{c} 1$ & kemauan dan motivasi & 20 \\
\hline 2 & $\mathrm{c} 2$ & kedisiplinan & 20 \\
\hline 3 & $\mathrm{c} 3$ & kondisi fisik & 15 \\
\hline 4 & $\mathrm{c} 4$ & pengalaman & 15 \\
\hline 5 & $\mathrm{c5}$ & ketahanan mental & 10 \\
\hline 6 & $\mathrm{c} 6$ & $\begin{array}{l}\text { spirit (semangat pantang } \\
\text { menyerah) }\end{array}$ & 10 \\
\hline 7 & $\mathrm{c} 7$ & postur tubuh & 10 \\
\hline
\end{tabular}

Pembobotan pada Tabel 1. merupakan bobot dasar yang menjadi acuan perhitungan awal yang berjumlah 100, batas pada jumlah seluruh bobot dalam kriteria adalah 150, jika dibutuhkan kriteria tambahan maka bobot kriteria baru tidak boleh menjadikan batas nilai bobot seluruh kriteria melebihi nilai 150. Pada kriteria masing - masing terdapat penilaian seperti pada Tabel 2. yaitu mempunyai nilai $1-5$, jika calon atlet tersebut dinilai sangat kurang dalam suatu kriteria, maka nilai calon atlet pada kriteria tersebut bernilai 1, jika dinilai kurang maka nilai calon atlet pada kriteria tersebut bernilai 2, jika dinilai cukup maka nilai calon atlet pada kriteria tersebut bernilai 3, jika dinilai baik maka nilai calon atlet pada kriteria tersebut bernilai 4 dan jika dinilai sangat baik maka nilai calon atlet pada kriteria tersebut bernilai 5. Tabel 2 berisi tentang keterangan nilai.

Tabel 2. Tabel keterangan nilai

\begin{tabular}{|l|l|l|}
\hline No. & Keterangan & Nilai \\
\hline 1 & sangat baik & 5 \\
\hline 2 & baik & 4 \\
\hline 3 & cukup & 3 \\
\hline 4 & kurang & 2 \\
\hline 5 & sangat kurang & 1 \\
\hline
\end{tabular}

Jika data nilai dari semua orang (alternatif) atau kriteria sudah lengkap maka akan dilakukan normalisasi dengan metode simple additive weighting (SAW), normalisasi dengan menggunakan metode simple additive weighting (SAW) jika kriteria tersebut bersifat benefit yaitu kriteria yang jika mempunyai nilai tertinggi dalam kriteria tersebut adalah yang terbaik, maka normalisasi dilakukan dengan rumus :

$$
r_{i j}=\frac{x_{i j}}{\operatorname{Max}_{i}\left(x_{i j}\right)}
$$

Setelah melakukan normalisasi menggunakan metode simple additive weighting, hasil normalisasi yang telah diperoleh dimasukkan ke dalam perhitungan matriks sebagai berikut: 


$$
\mathrm{R}=\left[\begin{array}{ccccccc}
1 & 0,75 & 1 & 1 & 0,6 & 0,8 & 1 \\
0,8 & 1 & 0,75 & 0,8 & 0,4 & 0,6 & 1 \\
0,4 & 1 & 0,5 & 0,6 & 1 & 1 & 0,8 \\
0,8 & 1 & 1 & 1 & 0,6 & 0,8 & 0,6 \\
0,4 & 0,75 & 0,8 & 0,8 & 1 & 1 & 0,4 \\
0,6 & 0,5 & 0,6 & 0,6 & 0,8 & 0,6 & 0,4
\end{array}\right]
$$

Setelah nilai kriteria ternormalisasi ke dalam matriks, dilanjutkan dengan perhitungan mencari nilai prefrensi yang menggunakan persamaan (2). Hasil perhitungan nilai Vi yang lebih besar mengindikasikan alternatif terbaik [10].

$V_{i}=\sum_{j=1}^{n} W_{j} r_{i j}$

Pada rumus mencari nilai prefrensi tersebut adalah jumlah total dari nilai bobot masing - masing dikalikan dengan nilai normalisasi masing - masing, pada nilai bobot masing - masing sudah terdapat pada tabel kriteria Tabel 1 , tetapi nilai pada masing masing bobot tersebut dibagi dengan jumlah nilai keseluruhan bobot yaitu dibagi dengan 100 dan dikalikan 100 persen agar total dari nilai pembobotan berjumlah 1, dan diperoleh sebagai berikut :

Tabel 3. Contoh penilaian akhir pembobotan

\begin{tabular}{|l|l|l|l|l|}
\hline No. & Keterangan & Simbol & Bobot & Nilai \\
\hline 1 & $\begin{array}{l}\text { kemauan dan } \\
\text { motivasi }\end{array}$ & c1 & 20 & 0,2 \\
\hline 2 & kedisiplinan & c2 & 20 & 0,2 \\
\hline 3 & kondisi fisik & c3 & 15 & 0,15 \\
\hline 4 & pengalaman & c4 & 15 & 0,15 \\
\hline 5 & ketahanan mental & c5 & 10 & 0,1 \\
\hline 6 & spirit & c6 & 10 & 0,1 \\
\hline 7 & postur tubuh & c7 & 10 & 0,1 \\
\hline
\end{tabular}

Dengan rumus dan nilai akhir pembobotan tersebut maka akan mendapat nilai prefrensi pada masing - masing baris (alternatif), perhitungannya sebagai berikut :

$V_{1}=(0,2 \times 1)+(0,2 \times 0,75)+(0,15 \times 1)+(0,1 \times 1)+(0,1 \times 0,6)+(0,1 \times 0,8)+(0,1 \times 1)=0,89$

$V_{2}=(0,2 \times 0,8)+(0,2 \times 1)+(0,15 \times 0,75)+(0,1 \times 0,8)+(0,1 \times 0,4)+(0,1 \times 0,6)+(0,1 \times 1)=0,79$

$V_{3}=(0,2 \times 0,4)+(0,2 \times 1)+(0,15 \times 0,5)+(0,1 \times 0,6)+(0,1 \times 1)+(0,1 \times 1)+(0,1 \times 0.8)=0,73$

$V_{4}=(0,2 \times 0,8)+(0,2 \times 1)+(0,15 \times 1)+(0,1 \times 1)+(0,1 \times 0,6)+(0,1 \times 0,8)+(0,1 \times 0.6)=0,86$

$V_{5}=(0,2 \times 0,4)+(0,2 \times 0,75)+(0,15 \times 0,5)+(0,1 \times 0,8)+(0,1 \times 1)+(0,1 \times 1)+(0,1 \times 0,4)=0,67$

$V_{6}=(0,2 \times 0,5)+(0,2 \times 0,6)+(0,15 \times 0,5)+(0,1 \times 0,6)+(0,1 \times 0,8)+(0,1 \times 0,6)+(0,1 \times 0,4)=0,57$

Setelah semua nilai prefrensi didapat, masing - masing dari nilai prefrensi tersebut dikalikan dengan ketereangan nilai tertinggi yaitu dikalikan dengan 5 agar didapat nilai hasil akhir, nilai hasil akhir berguna untuk menentukan lulus tidaknya calon atlet yang mengikuti seleksi pertandingan tersebut. Masing - masing pertandingan mempunyai batas nilai minimal pertandingan atau syarat nilai pertandingan. Syarat nilai pertandingan ditentukan oleh pelatih dan manager dengan meninjau tingkat pertandingan tersebut, semakin bergengsi dan semakin tinggi tingkat suatu pertandingan, maka akan semakin tinggi juga syarat nilai pertandingan tersebut. Pada contoh perhitungan kali ini memakai pertandingan tingkat provinsi pada provinsi Daerah Istimewa Yogyakarta, dan syarat nilai pertandingan yang diberikan oleh 
pelatih dan manager adalah 3,3, jadi nilai hasil akhir para calon atlet yang tepat ataupun melampaui syarat nilai pertandingan, maka akan dinyatakan lulus seleksi dan boleh mengikuti pertandingan tersebut. Contoh hasil akhir pada seleksi seperti berikut :

Tabel 4. Contoh hasil akhir penilaian

\begin{tabular}{|c|c|c|c|c|c|c|c|c|c|c|c|}
\hline \multirow{2}{*}{ No. } & \multirow{2}{*}{ nama } & \multicolumn{7}{|c|}{ Nilai Normalisasi (r) } & \multirow{2}{*}{$\begin{array}{l}\text { Prefrensi } \\
\text { (v) }\end{array}$} & \multirow{2}{*}{$\begin{array}{l}\text { Nilai } \\
\text { Akhir }\end{array}$} & \multirow{2}{*}{ status } \\
\hline & & $\mathrm{c} 1$ & $\mathrm{c} 2$ & c3 & c4 & $c 5$ & c6 & c7 & & & \\
\hline 1 & fachrizal & 1,00 & 0,75 & 1,00 & 1,00 & 0,60 & 0,80 & 1,00 & 0,89 & 4,45 & lulus \\
\hline 2 & ary & 0,80 & 1,00 & 0,75 & 0,80 & 0,40 & 0,60 & 1,00 & 0,79 & 3,9625 & lulus \\
\hline 3 & giffary & 0,40 & 1,00 & 0,50 & 0,60 & 1,00 & 1,00 & 0,80 & 0,73 & 3,625 & lulus \\
\hline 4 & mahendra & 0,80 & 1,00 & 1,00 & 1,00 & 0,60 & 0,80 & 0,60 & 0,86 & 4,3 & lulus \\
\hline 5 & elian & 0,40 & 0,75 & 0,50 & 0,80 & 1,00 & 1,00 & 0,40 & 0,67 & 3,325 & lulus \\
\hline 6 & frederic & 0,60 & 0,50 & 0,50 & 0,60 & 0,80 & 0,60 & 0,40 & 0,57 & 2,825 & gagal \\
\hline
\end{tabular}

\section{Hasil dan Pembahasan}

Pada bagian ini dibahas mengenai implementasi sistem dan menyajikan screenshoot aplikasi penentuan kelayakkan atlet yang dibangun.

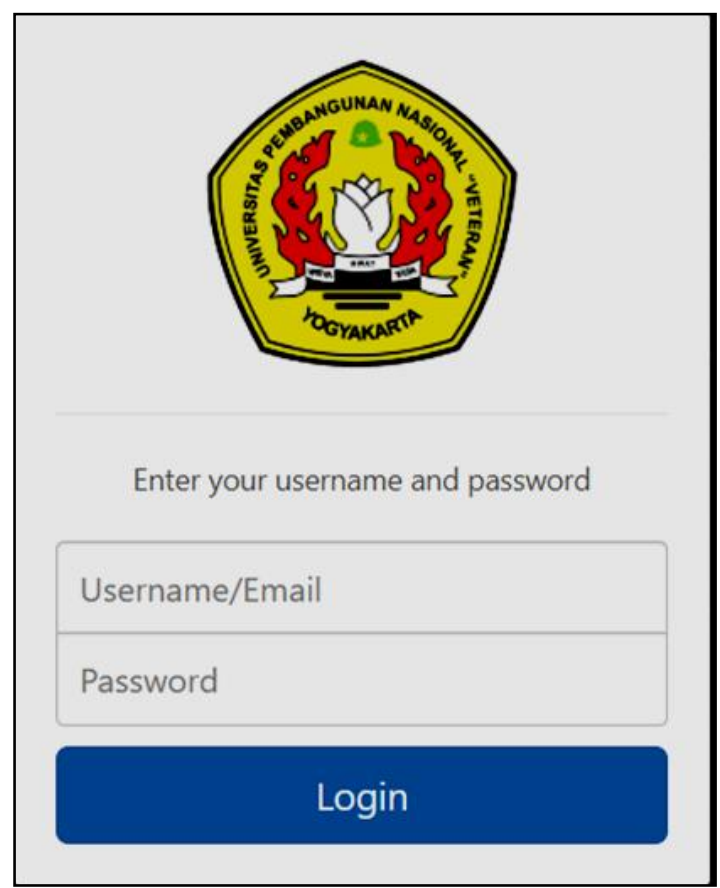

Gambar 2. Halaman Login Pengguna 
Pada laman login pengguna sistem yaitu admin melakukan login sebelum menjalan fungsi yang lain dari aplikasi.

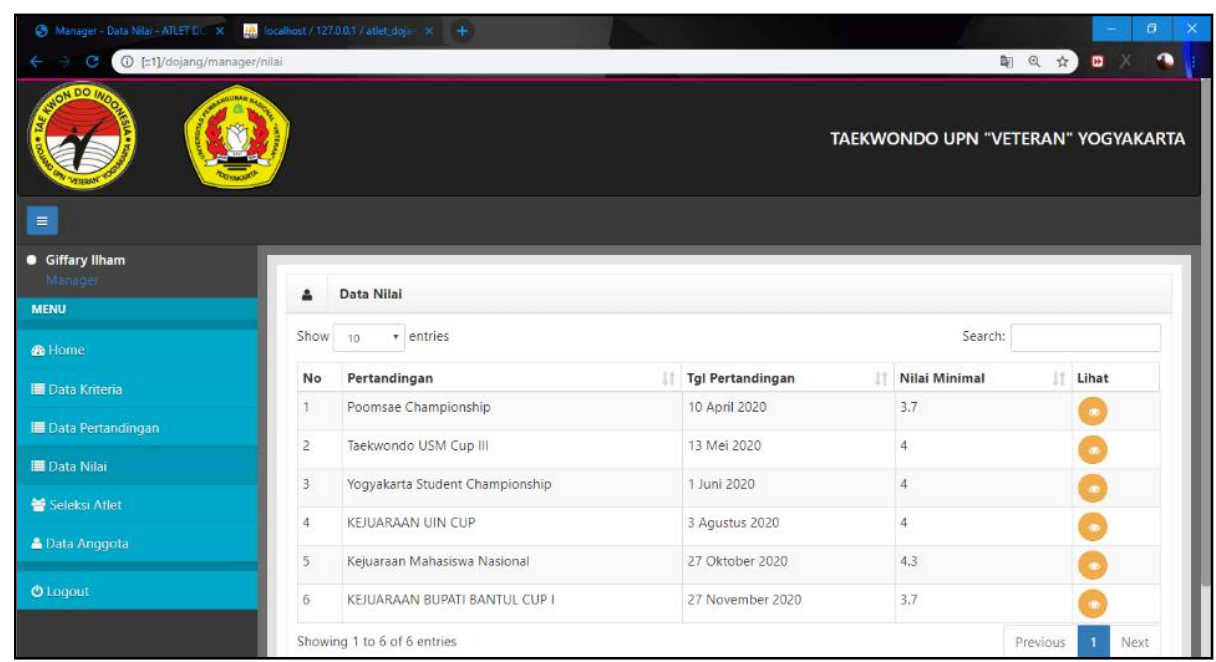

Gambar 3. Halaman Nilai Pertandingan

Halaman lihat data nilai merupakan halaman kumpulan data nilai anggota yang dimana para calon atlet telah diambil penilaian pada tahap seleksi pertandingan yang akan diikuti. Terdapat tabel data nilai calon atlet dan terdapat tombol edit yang jika dipilih akan menuju ke halaman kelola nilai.

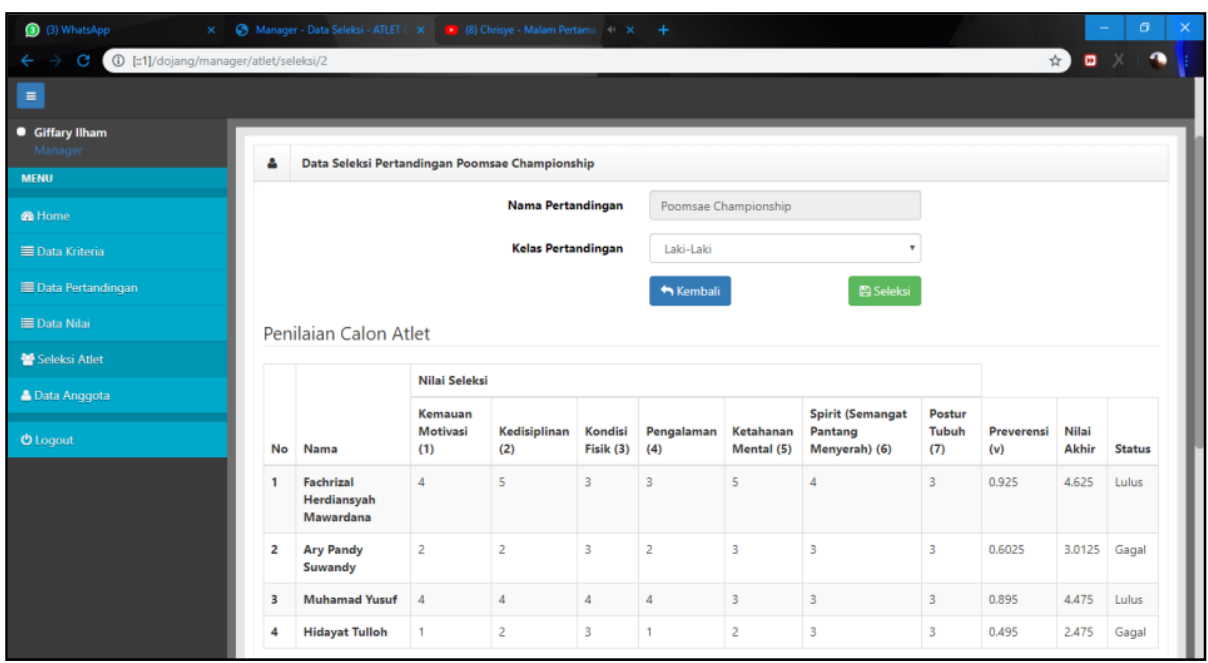

Gambar 4. Halaman Seleksi Pertandingan

Halaman seleksi pertandingan merupakan halaman penyeleksian calon atlet berdasarkan gender. Pada halaman ini, proses seleksi dilakukan berdasarkan gender yang prosesnya dilakukan sebanyak dua kali. Terdapat dua form yaitu form nama pertandingan dan form pilihan gender, proses penyeleksian dapat berjalan jika pada masing - masing kelas gender tidak mempunyai nilai yang kosong, jika nilai telah lengkap maka dengan menekan tombol seleksi kemudian proses akan berjalan, setelah dua proses seleksi telah dilakukan dengan menekan tombol selesai akan kembali pada halaman seleksi atlet.

\section{Kesimpulan}

Kesimpulan yang dapat diambil dari penelitian ini adalah metode Simple Additive Weighting dapat digunakan untuk menentukan kelayakkan Taekwondo di UPN "Veteran" Yogyakarta untuk menjadi atlet dalam partisipasi kejuaraan. Dynamic criteria dalam 
perhitungan dapat memudahkan manager dalam proses seleksi dan menentukan kelayakkan atlet taekwondo dalam partisipasi kejuaraan. Hasil pengujian menunjukkan aplikasi ini dapat diterima pengguna sebesar $85 \%$.

\section{Daftar Pustaka}

[1] Pitakasari, A. R. (2012, Juli 06). Prestasi Taekwondo Indonesia Dinilai WTF Meningkat. Diambil kembali dari Republika.co.id: https://www.republika.co.id/berita/olahraga/umum-2/12/07/07/m6r0ej-prestasitaekwondo-indonesia-dinilai-wtf-meningkat

[2] Setiaji, P. (2012). Sistem Pendukung Keputusan Dengan Metode Simple Additive Weighting. Simetris: Jurnal Teknik Mesin, Elektro dan Ilmu Komputer, 1(1), 59-67.

[3] Sanjaya, A. (2015, October 2). Metode Simple Additive Weighting (SAW) Langkah dan Kelebihan. Diambil kembali dari Landasan Teori: http://www.landasanteori.com/2015/10/metode-simple-additive-weighting-saw.html

[4] Wicaksono, D. H., 2013. Penerapan Metode Simple Additive Weighting Dalam Sistem Pendukung Keputusan Pemilihan Tablet.

[5] Rasyid, M., \& Si, M. B. S. (2017). Analisa Perbandingan Metode Simple Additive Weighting (SAW) DAN Metode Simple Multi Atribute Rating Technique (SMART) Dalam Pemberian Beasiswa (Studi Kasus Pemerintah Kota Batam).

[6] Jayanti, N. K. D. A. (2016). Implementasi Metode SAW Dan AHP Pada Sistem Informasi Penilaian Kinerja Dosen. CSRID (Computer Science Research and Its Development Journal), 8(2), 86-98.

[7] Jasril, J., Haerani, E., \& Afrianty, I. (2011, June). Sistem Pendukung Keputusan (SPK) Pemilihan Karyawan Terbaik Menggunakan Metode Fuzzy AHP (F-AHP). In Seminar Nasional Aplikasi Teknologi Informasi 2011. Islamic University of Indonesia.

[8] Pressman, R,. 2012. Software Engineering 7th edition, Prentice Hall.

[9] Deddy Mulyana, M. P., 2018. Metodologi Penelitian Kualitatif. Bandung: PT REMAJA ROSDAKARYA

[10] Nugroho, J. U., Bayu, S., \& Adi, K. (2013). Sistem Pendukung Keputusan Penilaian Proses Belajar Mengajar Menggunakan Metode Simple Additive Weighting (SAW) (Doctoral dissertation, Diponegoro University). 